\title{
Synovial Sarcoma in Pediatric Age Group: Single Center Experience
}

\section{Çocukluk Çağı Döneminde Sinoviyal Sarkom: Tek Merkez Deneyimi}

\author{
Turan Bayhan ${ }^{1}$, Neriman Sarı ${ }^{1}$, Ebru Atasever Akkaş² ${ }^{2}$ İnci Ergürhan İlhan ${ }^{1}$ \\ ${ }^{1}$ Çocuk Hematoloji ve Onkoloji Kliniği, Ankara Onkoloji Eğitim ve Araştırma Hastanesi \\ ${ }^{2}$ Radyasyon Onkolojisi Kliniği, Ankara Onkoloji Eğitim ve Araştırma Hastanesi
}

Dergiye Ulaşma Tarihi: 07.09.2018 Dergiye Kabul Tarihi: 18.12.2018 Doi: 10.5505/aot.2019.70783

\section{ÖZET}

GíRiş ve AMAÇ: Sinoviyal sarkom (SS) çocukluk çağının en sık rabdomyosarkom dışı yumuşak doku sarkomu olmakla birlikte erişkin yaş grubunda daha sık görülür. Çalışmamızda merkezimizde izlenen SS tanılı çocuk hastaların klinik bulgu ve tedavi sonuçlarını geriye dönük olarak incelemeyi amaçladık.

YÖNTEM ve GEREÇLER: Ankara Onkoloji Eğitim ve Araştırma Hastanesi Çocuk Hematoloji Onkoloji Kliniği'nde 1993 ile 2017 yılları arasında SS tanısı almış hastalar değerlendirildi. Hastaların klinik özellikleri, aldıkları tedaviler ve tedaviye yanıtları incelendi.

BULGULAR: Kliniğimizde izlenen 15 çocuk hastanın verilerine ulaşıldı. Hastaların yaş ortancası 14,5 (13 17) yıldı, 14 hastada tümör ekstremite kökenliydi. Hastalar IRS gruplama sistemine göre değerlendirildiğinde beş hasta $(\% 33,3)$ grup I, sekiz hasta $(\% 53,3)$ grup II ve iki hasta $(\% 13,3)$ grup III'tü. İlk remisyon sağlanan 12 hastanın dördünde (\%33) rölaps gelişti, üç hastada sadece akciğer, bir hastada akciğer ve eksternal iliak lenf düğümünde hastalık tespit edildi. Hastalar ortanca 28 (5 - 85) ay izlendi, üç yıllık olaysız sağ kalım $\% 53,6$, üç yıllık genel să kalım \%73 olarak hesaplandı. Hastaların IRS gruplarına göre üç yıllık genel sağ kalımları karşılaştırıldığında IRS grup I; \%75, IRS grup II; \%100 ve IRS grup III'te \%0’dı (p; <0,001).

TARTIŞMA ve SONUÇ: Çocukluk çağında SS yeterli cerrahi yapılamadığında prognozu oldukça kötü bir tümördür. Remisyon sağlanan hastalarda bile akciğer en sık relaps yeridir, kontrollerde küçük akciğer nodülleri tespit edildiğinde akciğer relapsı açısından dikkatli izlenmelidir. Ülkemizde yapılacak çok merkezli çalışmalarla çocukluk çağ 1 SS hakkında genel geçerliliği olan veriler elde edilebilir.

Anahtar Kelimeler:Akciğer nodülleri, çocuk, prognoz,sinoviyal sarkom

\begin{abstract}
INTRODUCTION: Synovial sarcoma (SS) is generally observed in adults, however it is the most common nonrhabdomyosarcoma soft tissue sarcoma during childhood. In our study we reviewed pediatric patients with SS followed in our clinic retrospectively.

METHODS: Patients with SS diagnosed between 1993 and 2017 in Ankara Oncology Training and Research Hospital included into the study. Their files were reviewed retrospectively, clinical presentation, treatments and response of patients to treatment were investigated.

RESULTS: We analyzed data of 15 pediatric patients. Median age of patients was 14.5 (13 - 17) years, in 14 patients tumor was located in extremities. When we grouped patients based on IRS staging; five patients (33.3\%) were in group I, eight patients (53.3\%) were in group II, and two patients $(13.3 \%)$ were in group III. Four (33\%) of the 12 patients that in first remission relapse occurred; in three patients there was isolated lung relapse and in one patient relapse was from lung and external iliac lymph node. Patients were followed median $28(5-85)$ months, three years event free survival was $53.6 \%$, and overall survival was $73 \%$. When we compared three years overall survival of patients based on IRS staging; $75 \%$ in IRS group I; $100 \%$ in IRS group II; and $0 \%$ in IRS group III ( $\mathrm{p} ;<0.001)$.

DISCUSSION and CONCLUSION: Prognosis of synovial sarcoma during childhood is very bad if surgery is not performed. In patients with remission lung is the most common region for relapse, and patients should be followed carefully for relapse if unspecified small pulmonary nodules are detected. Multi-centric studies with more patients in our country should be performed to get more valid information about our country.
\end{abstract}

Key Words: Children, prognosis, pulmonary nodule, synovial sarcoma

\section{GíRIŞ}

Sinoviyal sarkom (SS), bölgesel yayılım ve metastaz yapmaya eğilimli, yüksek dereceli bir yumuşak doku sarkomudur. Her yaşta görülebilmekle birlikte en s1k otuzlu yaşlarda görülür. Hastaların ancak \%30’u 20 yaş altındadır $(1,2)$. Yirmi yaş altı çocuk ve 
Orijinal Çalışma

adolesanlarda y1ll1k insidansi 0,50,7/milyondur (1, 3). Sinoviyal sarkom nadir bir tümör olmasına rağmen çocukluk çağının en sık rabdomyosarkom dişı yumuşak doku sarkomudur (4). Olguların \%66'sinda kitle ekstremitelerde ve eklemlerden uzak ortaya çıkmakla birlikte vücudun herhangi bir yerinde de görülebilir (5). Histolojik olarak iki tipi vardır; bifazik tip hem epitelyum benzeri hem de iğsi hücreler içerir, monofazik tip ise sadece iğsi hücrelerden oluşur. Histolojik tipin prognozla ilişkisi yoktur $(1,5)$. Kromozom 18 ve $\mathrm{X}$ arasındaki translokasyon sonucu oluşan SYT-SSX1 ve SYT-SSX2 genleri SS için özgün belirteçlerdir ve hastaların $\% 90$ 95'inde pozitiftir (6).

Çocukluk çağında da erişkin döneminde olduğu gibi SS tedavisinin ilk basamağ 1 tümörün cerrahi sınırlarının negatif olarak çıkarılmasıdır (7). İlk cerrahi mümkün değilse biyopsi alınıp cerrahi neoadjuvan kemoterapi sonrasına ertelenmelidir (1). Sinoviyal sarkomun patolojik ve klinik özellikleri erişkin ve çocukta aynı olmasına rağmen, her iki grubun tedavide farklı yaklaşımları vardır. Medikal onkologlar bu tümörü kemoterapiye dirençli kabul edip daha çok tümörün bölgesel kontrolünün sağlanmasına odaklanırken; çocuk onkologları tümörü kemoterapiye hassas sayarak sistemik kemoterapi kullanma eğilimindedirler (8). Çocukluk döneminde görülen SS ile literatürde sinırlı da olsa yayınlar bulunmaktadır, ülkemizden çocukluk çağında nadir tümörlerle ilgili yapılan bir çalışmada ise dört SS tanılı olgu bildirilmiştir (9). Ülkemizden yayınlanan çocukluk çağında geniş seriler olmadığı için merkezimizin SS deneyimini geriye dönük olarak değerlendirdik.

\section{GEREÇ ve YÖNTEM}

Çalışma Ankara Onkoloji Hastanesi Çocuk Hematoloji Onkoloji Kliniği'nde gerçekleştirildi. Kliniğimizde 1993 ile 2017 yılları arasında SS tanısı almış hastaların dosyaları geriye dönük olarak incelendi, tanı için hastaların patoloji raporları esas alındı. Çalışma için kurumsal etik kurul onayı alındı. Hastaların dosyalarından başvurudaki klinik özellikleri, radyolojik görüntüleme ve patoloji raporlar1, radyoterapi dozları, kemoterapi şemaları öğrenildi. Tümör boyutu tanı anındaki manyetik rezonans görüntülemedeki en büyük çap kabul edildi. Cerrahi sonrası evrelemede
Rabdomyosarkom Çalışma Grubu (Intergroup Rhabdomyosarcoma Study; IRS) gruplama sistemi kullanıldı. Buna göre: IRS grup I; cerrahi olarak tamamen tümör çıkarılmış, IRS grup II; cerrahi sınırda mikroskobik tümör kalıntıs1 bulunmas1, IRS grup III; cerrahi sonrası büyük kitle kalması, IRS grup IV; tanı anında metastatik hastalık bulunmasidir (10). Hastalar ifosfamid (bir hastada siklofosfamid) ve adriamisin içeren kemoterapi protokolleri ile tedavi edildi. İstatistiksel analiz için SPSS versiyon 21 programı kullanıldı. Tanımlayıc1 istatistikler analizlerle veriler incelendi, sağ kalım analizi Kaplan - Meier yöntemi ile yapild.

\section{BULGULAR}

Çalışmada 15 hastanın verilerine ulaşıldı. Hastaların yaş ortancası 14,5 (13 - 17) yıl, erkek/kız oran $13 / 2$ 'iydi. Tanı anında tümör bir hastada $(\% 6,7)$ toraks yerleşimli iken diğer 14 hastada (\% 93,7) ekstremitedeydi. Ekstremite tümörlerinin dokuzu $(\% 64,3)$ sağ, beşi $(\% 35,7)$ sol taraftaydı. Ortanca tümör çap1 $8 \mathrm{~cm}$ olup 2,3 $-18 \mathrm{~cm}$ arasında değişmekteydi (Tablo 1). Dört hastanın tanı anında, ameliyat olmadan çekilmiş FDG pozitron emisyon tomografisi (PET) taraması vardı. PET çekilen dört hastada da kitlede aktif tutulum bulunmaktayd. Tanı anında hastaların hiçbirinde metastaz tespit edilmedi.

On dört hastaya tümörün çıkarılması için cerrahi işlem uygulanırken bir hastanın ailesi amputasyonu kabul etmediğinden cerrahi işlem uygulanamadi. Cerrahi işlem iki hastada amputasyon, torakal kitlesi olan bir hastada kısmi rezeksiyon, diğer 11 hastada geniş tümör rezeksiyonu olarak gerçekleştirildi. Amputasyon yapılan iki hastada ve geniş rezeksiyon yapılan hastaların üçünde cerrahi sınır negatif, diğer sekizinde ise cerrahi sınır pozitifti. Hastalar IRS gruplama sistemine göre değerlendirildiğinde beş hasta $(\% 33,3)$ grup I, sekiz hasta grup II $(\% 53,3)$ ve iki hasta $(\% 13,3)$ grup III'tü. Amputasyon yapılmayan 13 hastaya radyoterapi verildi, ortanca radyoterapi dozu 63 (21,6 - 72) Gy'di. Bir hastada radyoterapi sirasinda operasyon yerinde enfeksiyon gelişti ve radyoterapi uygun dozda verilemeden 21,6 Gy'lik tedavi sonras1 kesildi. Radyoterapi alan hastaların dördünde (\%31) radyoterapiye ikincil ağır dermatit gelişti. Hastaların hepsi ifosfamid (bir hastada siklofosfamid) ve adriamisin içeren 


\section{Orijinal Çalışma}

kemoterapi rejimi ile tedavi edildi. Bir hastanın vincristin adriamisin, ifosfamid, aktinomisin-d içeren kemoterapi rejiminin dördüncü küründen sonra ağır radyasyon dermatiti oldu, kemoterapisine üç ay ara verilen hastanın kemoterapisi kesildi. Üç hastada ilk kemoterapi rejimi sirasinda hastalık progresyonu oldu, bu hastalardan ikisi eksitus olurken bir hasta ifosfamid, karboplatin ve etoposid (ICE) içeren tedavi protokolü ile remisyona girdi. Torakal kitlesi olan hastanın tümörü cerrahi olarak tam çıkarılamadı, tümör vinkristin, adriamisin, ifosfamid, aktinomisin d (VAIA) ve ICE kemoterapileri ile küçülmedi, pazopanib başlanan hasta tedavinin birinci ayında başka bir şehirde ani gelişen solunum sıkıntıs1 ve pnömotoraks nedeniyle eksitus oldu. İlk remisyon sağlanan 12 hastanın dördünde (\%33) rölaps gelişti, ortanca relaps gelişme süresi dokuz $(2-48)$ aydı. Üç hastada akciğer metastazı bir hastada akciğer ve lenf düğümü (eksternal ilik lenf düğümü) metastazı oldu, hiçbir hastada primer tümör bölgesinden rölaps olmadı. İki hasta rölaps sonrası tedaviyi kabul etmedi ve eksitus oldu, bir hastada 10 kür ICE tedavisi sonrası (altıncı kürden itibaren tedavi etopozidsiz verildi) ikinci rölaps gelişti ve hasta eksitus oldu. Bu hastanın ikinci relaps1 akciğerden ve primer tümör bölgesindendi. Relaps olan diğer hastaya irinotekan ve temazolamidden oluşan tedavi üç kür verildi, progresyonu olması üzerine hastaya pazopanib başland1, pazopanib tedavisinin altıncı ayında hasta halen parsiyel remisyonda izlenmektedir.

Hastalar ortanca $28(5-85)$ ay izlendi, üç yıllık olaysız sağ kalım \%53,6, üç yıllık genel sağ kalım \%73 olarak hesaplandi. Hastaların IRS gruplarına göre üç yıllık genel să̆ kalımları karşılaştırıldığında IRS grup I; $\% 75$, IRS grup II; \%100 idi ve IRS grup III'te sağ kalım yoktu (p; <0,001).

\section{TARTIŞMA}

Sinoviyal sarkom, adlandirmasinın aksine sinoviyal zardan değil primitif mezenkimal hücrelerden köken alan bir tümördür. Hastaların \%66 - 70'inde ekstremitelerde, özellikle büyük eklem komşuluğunda olsa da vücudun her hangi bir yerinde, eklemlerden uzakta da oluşabilir (1, 4, 5). Ekstremite kökenli SS tanılı hastaların da \%70 - 81'inde tümör alt ekstremiteden kaynaklanır $(4,11)$.
Çalışmamızda tümör, 15 hastanın 14'ünde ekstremite kökenliydi ve bu hastaların 13'ünde alt ekstremitede gelişmişti. Ekstremite kökenli hastaların literatüre göre merkezimizde daha s1k görülmesinin $(\% 93,7)$ nedeni merkezimizin kemik tümörlerinde deneyimli olması ve seçilmiş hastaların merkezimizin Ortopedi Kliniği'ne yönlendirilmiş olmasındandır. $\mathrm{Bu}$ çalışmada ayrıca ekstremitede tümörü olan hastaların \%64,3'ünde tümör hastanın sağ tarafında tespit edilmişti. Literatürde bu bilgiyi destekler bir veriye rastlanmadı, ancak daha fazla hasta ile yapılacak çalışmalar ile tümörün bulunduğu tarafin sıklığının önemi araştırılabilir.

Çalışmamızda dört hastada rölaps görüldü, ilk rölapsların hiçbiri lokal değildi ve hepsinde akciğer metastazı mevcuttu. Sadece bir hastada ikinci rölaps sırasında akciğer metastazı yanında lokal hastalık gelişti. Avrupa Pediatrik Yumuşak Doku Sarkomu Çalışma Grubu'nun prospektif bir çalışmasında relaps gelişen SS tanıl1 27 hastanın \%44'ünde izole akciğer metastazı görülürken \%37'sinde lokal rölaps olmuştur (8). Soole ve arkadaşlarının rölaps SS tanılı çocuk hastaları inceledikleri çalışmalarında ise rölapsların çoğunluğu (\%73) lokal olmuştur ve beş yıllık sağ kalımları \% 42,1 bulunmuştur (12). Rölaps SS tanılı hastaların prognozu bizim serimizde de çok kötü seyretti ve dört hastadan sadece biri parsiyel remisyona girdi. Pazopanib ağızdan kullanılan çok hedefli bir tirozin kinaz inhibitörüdür ve yumuşak doku sarkomlarında ikinci ve üçüncü aşama tedavi seçeneği olarak etkinliği gösterilmiştir (13). Pazopanibin önemli bir yan etkisi spontan pnömotorakstır (14). Pazopabib tedavisi altında ani gelișen solunum sikıntısı ile kaybedilen hastamız başka bir şehirde eksitus olduğu için torakal kitlesinden mi pnömotoraks nedeniyle mi eksitus olduğu anlaşılamamıştır. Progresyon ve rölaps gelişen diğer hastalarda o dönem pazopanib kullanımda olmadığ 1 için denenememiştir. Pazopanib ileride tedaviye dirençli hastalarda öncelikli bir ilaca dönüşebilir, ama bu konuda geniş çaplı çalışmalara ihtiyaç vardır.

Çalışmamızda cerrahi öncesi PET çekilen dört hastanın dördünde de tümörde tutulum olduğu görülmüştür. Bir erişkin çalışmasında SS tanılı hastalarda PET taramasının duyarlılığ $\quad \% 80$ olarak bulunmuştur (15). Çocukluk çağındaki SS tanılı hastalarda PET taramasının kullanımına 


\section{Orijinal Çalışma}

dair bir çalışma henüz yapılmamıştır. Çalışmamızda az sayıda hastada PET taraması yapılmış olsa da hepsinde tutulum olduğu görülmüştür ve bu durum PET taramasının çocukluk döneminde kullanılmasının düşünülebileceğini göstermiştir.

Sinoviyal sarkom yavaş büyüyen bir tümördür ve bu nedenle ilk fark edildiğinde yanlışlıkla iyi huylu bir tümör sanılabilir (1). Benzer şekilde tanı anında hastalar nadiren metastazla gelmektedir, tan 1 anında metastaz varlığ1 \%5,8 olarak bildirilmiştir ve bu metastazların \%85'i akciğerlere olur (16). Bizim serimizde tanı anında hastaların hiçbiri metastatik değildi, ancak rölaps olan dört hastada da akciğer metastazı gelişti. Rölaps olan üç hastanın tedavi kesimi sonrası izlemlerinde akciğer tomografilerinde 5 mm'den küçük nodüller tespit edildi. $\mathrm{Bu}$ nodüllerin ilerleyen dönemde sayılarının arttı̆g 1 ancak boyutlarında belirgin bir şekilde artmadığ1 gözlendi. Bu durum akciğeri tutan kanser hücrelerinin primer kitle gibi belki de daha da yavaş büyümesiyle açıklanabilir, tanı anında akciğeri tutulu olsa da yavaş büyüyen küçük nodüller tanı almayı güçleştiriyor olabilir. Bu hastaların takibinde sayısı az ve boyutu küçük de olsa tüm nodüller yakından izlenmeli ve nodüller $5 \mathrm{~mm}$ 'den küçük olsa da biyopsi alınmalıdır.

Çalışmamızda üç yıllık genel sağ kalım $\% 73$, olaysız sağ kalım ise $\% 53,6$ hesaplanmıştır. Literatürde beş yıllık sağ kalım $\% 62,8$ ile \%90,7 arasında bildirilmektedir (1, $4,8,11)$. Daha önceki çalışmalarda prognozu etkileyen en önemli iki faktör; tümörün evresi ve boyutu olarak bildirilmiştir $(11,17)$. Bizim serimizde de IRS grubuna göre hastaların sağ kalımında istatistiksel olarak anlamlı fark bulundu, IRS grup III hastalarda üç yıllık sağ kalım \%0 olarak hesaplad1. IRS grup I hastaların sağ kalımı grup II'deki hastalara göre daha kötü gibi görünse de $(\% 75$ 'e $\% 100)$ bu durum hasta sayısının az olması ve üç yıllık sağ kalıma göre değerlendirme yapılması nedeniyle olabilir. Daha önceki çalışmalarda tümör boyutu $5 \mathrm{~cm}$ 'den büyük olan hastalarda beş yıllık săg kalımın daha düşük olduğu gösterilmiştir $(7,11)$. Çalışmamızda hastaların sadece üçünde tümör boyutu $\leq 5 \mathrm{~cm}$ olduğu için tümör boyutuna göre sağ kalım karşılaştırılamadı. Almanya, İtalya ve Amerika Birleşik Devletleri'nden bildirilen çok merkezli çalışmalarda, tümör boyutu yanı sıra tümörün komşu organları tutması da kötü prognostik bir etken olarak bulunmuştur $(3,7$, 11). Ayrıca literatürde ekstremitede bulunan tümörlerin sağ kalımı gövdedekilere göre daha iyi olarak bildirilmiştir, ancak çalışmamızda bu karşılaştırma da gerçekleştirilemedi (2). Bunun yanı sıra, Stanelle ve arkadaşları üst ekstremite tümörlerinin sağ kalımının alt ekstremite kökenli tümörlere göre daha iyi olduğunu ileri sürmüşlerdir (11). Çocuk çağ $1 \mathrm{SS}$ serilerinde, hastaların ancak \%46 - 54'ünde tanı anında tümör boyutunun $>5 \mathrm{~cm}$ olduğu bildirilmiştir $(4,12)$. Çalışmamızda ise hastaların büyük çoğunluğunun (\%80) tanı anında tümör boyutunu $>5 \mathrm{~cm}$ idi, bu durum ülkemizde çocukluk çağında SS tanısı konulmasında güçlük yaşandığını gösteriyor olabilir. Ayrıca hastaların \%80'inde tümör boyutunun $>5 \mathrm{~cm}$ olmas1 ve iki hastada tümörün tam çıkarılamamasına rağmen üç yıllık sağ kalımın \%73 olması başarılı bir sonuç kabul edilebilir.

Sonuç olarak çocukluk çağında SS yeterli cerrahi yapılamadığında prognozu oldukça kötü bir tümördür, remisyon sağlanan hastalarda milimetrik akciğer nodülleri akciğer metastazı açısından dikkatli izlenmelidir. Ülkemizde yapılacak çok merkezli çalışmalarla çocukluk çağı SS hakkında ülkemize has genel veriler elde edilebilir.

Çıkar Çatışması: Yok. 


\section{Orijinal Çalışma}

Tablo 1:Hastaların klinik özellikleri

\begin{tabular}{|c|c|c|c|c|c|c|c|c|c|}
\hline $\begin{array}{l}\text { Hasta } \\
\text { No }\end{array}$ & $\begin{array}{l}\text { Yaş, } \\
\text { cinsiyet }\end{array}$ & $\begin{array}{l}\text { Tümör } \\
\text { yeri }\end{array}$ & $\begin{array}{l}\text { Tümör } \\
\text { boyut } \\
(\mathrm{cm})\end{array}$ & $\begin{array}{l}\text { IRS } \\
\text { grup }\end{array}$ & $\begin{array}{l}\text { Radyoterapi, } \\
\text { doz (Gy) }\end{array}$ & $\begin{array}{l}\text { İlk } \\
\text { kemoterapi, } \\
\text { kür sayıs1 }\end{array}$ & $\begin{array}{l}\text { Rölaps, } \\
\text { progresyon, } \\
\text { kemoterapi }\end{array}$ & $\begin{array}{l}\text { İzlem } \\
\text { süresi } \\
\text { (ay) }\end{array}$ & Son durum \\
\hline 1 & $14, \mathrm{E}$ & $\begin{array}{l}\text { Să̆ } \\
\text { diz }\end{array}$ & 2,3 & 1 & Var, 63 & VAIA, 14 & Yok & 31 & Remisyonda \\
\hline 2 & $16, \mathrm{E}$ & $\begin{array}{l}\text { Sağ } \\
\text { ayak } \\
\text { bileği }\end{array}$ & 4 & 2 & Var, 66 & VAIA, 4 & Yok & 17 & Remisyonda \\
\hline 3 & $17, \mathrm{~K}$ & $\begin{array}{l}\text { Sol } \\
\text { uyluk }\end{array}$ & 11,2 & 2 & Var, 62 & VAIA, 14 & Yok & 18 & Remisyonda \\
\hline 4 & $14,5, \mathrm{~K}$ & $\begin{array}{l}\text { Sağ } \\
\text { uyluk }\end{array}$ & 8,1 & 2 & Var, 66 & VAIA, 14 & Yok & 64 & Remisyonda \\
\hline 5 & $16, \mathrm{~K}$ & $\begin{array}{l}\text { Sağ } \\
\text { uyluk }\end{array}$ & 11 & 2 & Var, 66 & $\begin{array}{l}\text { Ifosfamid + } \\
\text { adriamisin, } \\
6\end{array}$ & Yok & 5 & Remisyonda \\
\hline 6 & $14, \mathrm{E}$ & $\begin{array}{l}\text { Sol } \\
\text { uyluk }\end{array}$ & 8 & 2 & Var, 21,6 & VAIA, 13 & $\begin{array}{l}\text { Rölaps; } \\
\text { irinotekan + } \\
\text { temazolamid } \\
\text { x } 3 \text { kür, } \\
\text { progresyonda } \\
\text { pazopanib }\end{array}$ & 28 & $\begin{array}{l}\text { Parsiyel } \\
\text { remisyon }\end{array}$ \\
\hline 7 & $14,5, \mathrm{~K}$ & $\begin{array}{l}\text { Sağ } \\
\text { dirsek }\end{array}$ & 7,5 & 2 & Var, 72 & VAIA, 14 & $\begin{array}{l}\text { Rölaps; } \\
\text { ikinci } \\
\text { basamak } \\
\text { tedaviyi } \\
\text { kabul etmedi }\end{array}$ & 45 & Eksitus \\
\hline 8 & $13,5, \mathrm{~K}$ & $\begin{array}{l}\text { Sağ } \\
\text { uyluk }\end{array}$ & 18 & 3 & Var, 64 & EVAIA, 9 & $\begin{array}{l}\text { Progresyon, } \\
\text { ikinci } \\
\text { basamak } \\
\text { tedaviyi } \\
\text { kabul etmedi. }\end{array}$ & 10 & Eksitus \\
\hline 9 & $16, \mathrm{E}$ & $\begin{array}{l}\text { Sol } \\
\text { ayak } \\
\text { bileği }\end{array}$ & 3 & 1 & $\begin{array}{l}\text { Yok } \\
\text { (ampute) }\end{array}$ & VACA, 12 & $\begin{array}{l}\text { Rölaps; ICE } \\
\text { x } 10 \text { kür, } \\
\text { ikinci } \\
\text { rölapsta } \\
\text { tedavi yok } \\
\end{array}$ & 29 & Eksitus \\
\hline 10 & $15, \mathrm{E}$ & $\begin{array}{l}\text { Sağ } \\
\text { uyluk }\end{array}$ & 10 & 1 & $\begin{array}{l}\text { Yok } \\
\text { (ampute) }\end{array}$ & EVAIA, 12 & Yok & 67 & Remisyonda \\
\hline 11 & $13, \mathrm{E}$ & Toraks & 14 & 3 & Var, 45 & VAIA, 6 & $\begin{array}{l}\text { Progresyon; } \\
\text { ICE x } 6 \text { kür, } \\
\text { ikinci } \\
\text { progresyonda } \\
\text { pazopanib } \\
\text { başalandı }\end{array}$ & 12 & Eksitus \\
\hline 12 & $17, \mathrm{E}$ & $\begin{array}{l}\text { Sağ } \\
\text { uyluk }\end{array}$ & 6 & 2 & Var, 65 & VAIA, 14 & $\begin{array}{l}\text { Rölaps, } \\
\text { ikinci } \\
\text { basamak } \\
\text { tedaviyi } \\
\text { kabul etmedi. }\end{array}$ & 85 & Eksitus \\
\hline 13 & $14, \mathrm{~K}$ & Sol diz & 9 & 2 & Var, 59 & VAIA, 5 & $\begin{array}{l}\text { Progresyon, } \\
\text { ICE x } 3 \text { kür }\end{array}$ & 10 & Remisyonda \\
\hline 14 & $16,5, \mathrm{E}$ & $\begin{array}{l}\text { Sağ } \\
\text { diz }\end{array}$ & 8 & 1 & Var, 55,8 & VAIA, 14 & Yok & 23 & Remisyonda \\
\hline 15 & $13, \mathrm{E}$ & $\begin{array}{l}\text { Sol, } \\
\text { uyluk }\end{array}$ & 8 & 1 & Var, 60 & VAIA, 14 & Yok & 65 & Remisyonda \\
\hline
\end{tabular}

E; erkek, K; kı, VAIA; vinkristin, aktinomisin d, ifosfamid, adriamisin, EVAIA; etopozid, vinkristin, aktinomisin d, ifosfamid, adriamisin, VACA; vinkristin, aktinomisin d, siklofosfamid, adriamisin, ICE; ifosfamid, karboplatin, etopozid 


\section{Orijinal Çalışma}

\section{REFERANSLAR}

1. Kerouanton A, Jimenez I, Cellier C, Laurence V, Helfre S, Pannier S, et al. Synovial sarcoma in children and adolescents. J Pediatr Hematol Oncol 2014;36(4):257-62

2. Speth BM, Krieg AH, Kaelin A, Exner GU, Guillou $\mathrm{L}$, von Hochstetter A, et al. Synovial sarcoma in patients under 20 years of age: a multicenter study with a minimum follow-up of 10 years. J Child Orthop 2011;5(5):335-42

3. Okcu MF, Munsell M, Treuner J, Mattke A, Pappo A, Cain A, et al. Synovial sarcoma of childhood and adolescence: a multicenter, multivariate analysis of outcome. J Clin Oncol 2003;21(8):1602-11

4. Brennan B, Stevens M, Kelsey A, Stiller CA. Synovial sarcoma in childhood and adolescence: a retrospective series of 77 patients registered by the Children's Cancer and Leukaemia Group between 1991 and 2006. Pediatr Blood Cancer 2010;55(1):8590

5. Orbach D, Mc Dowell H, Rey A, Bouvet N, Kelsey A, Stevens MC. Sparing strategy does not compromise prognosis in pediatric localized synovial sarcoma: experience of the International Society of Pediatric Oncology, Malignant Mesenchymal Tumors (SIOP-MMT) Working Group. Pediatr Blood Cancer 2011;57(7):1130-6

6. Lagarde P, Przybyl J, Brulard C, Perot G, Pierron G, Delattre $\mathrm{O}$, et al. Chromosome instability accounts for reverse metastatic outcomes of pediatric and adult synovial sarcomas. J Clin Oncol 2013;31(5):608-15

7. Brecht IB, Ferrari A, Int-Veen C, Schuck A, Mattke AC, Casanova M, et al. Grossly-resected synovial sarcoma treated by the German and Italian Pediatric Soft Tissue Sarcoma Cooperative Groups: discussion on the role of adjuvant therapies. Pediatr Blood Cancer 2006;46(1):11-7

8. Ferrari A, De Salvo GL, Brennan B, van Noesel MM, De Paoli A, Casanova M, et al. Synovial sarcoma in children and adolescents: the European Pediatric Soft Tissue Sarcoma Study Group prospective trial (EpSSG NRSTS 2005). Ann Oncol 2015;26(3):56772
9. Tacyildiz N, Ozyörük D, Yavuz G, Unal EC, Dinçaslan H, Tanyıldız GO, et al. Rare childhood tumors in Turkish pediatric oncology center. Indian J Med Pediatr Oncol 2013; 34(4):264-9

10. Maurer HM, Beltangady M, Gehan EA, Crist W, Hammond D, Hays DM, et al. The Intergroup Rhabdomyosarcoma Study-I. A final report. Cancer 1988;61(2):209-20

11. Stanelle EJ, Christison-Lagay ER, Healey JH, Singer S, Meyers PA, La Quaglia MP. Pediatric and adolescent synovial sarcoma: multivariate analysis of prognostic factors and survival outcomes. Ann Surg Oncol 2013;20(1):73-9

12. Soole F, Maupain C, Defachelles AS, Taque S, Minard-Colin V, Bergeron C, et al. Synovial sarcoma relapses in children and adolescents: prognostic factors, treatment, and outcome. Pediatr Blood Cancer2014;61(8):1387-93

13. Gelderblom H, Judson IR, Benson C, Merimsky O, Grignani G, Katz D, et al. Treatment patterns and clinical outcomes with pazopanib in patients with advanced soft tissue sarcomas in a compassionate use setting: results of the SPIRE study. Acta Oncol 2017;56(12):1769-75

14. Celik B, Surucu ZP, Yilmaz V, Celik HK. A Case Report of Secondary Simultaneous Bilateral Pneumothorax Due to Pazopanib Treatment. Turk Thorac J 2018;19(1):49-51. doi: 10.5152/TurkThoracJ.2018.030118.

15. Charest $M$, Hickeson M, Lisbona R, Novales-Diaz JA, Derbekyan V, Turcotte RE. FDG PET/CT imaging in primary osseous and soft tissue sarcomas: a retrospective review of 212 cases. Eur J Nucl Med Mol Imaging 2009;36(12):1944-51

16. Ferrari A, De Salvo GL, Oberlin O, Casanova M, De Paoli A, Rey A, et al. Synovial sarcoma in children and adolescents: a critical reappraisal of staging investigations in relation to the rate of metastatic involvement at diagnosis. Eur $\mathrm{J}$ Cancer 2012;48(9):1370-5

17. Ferrari A, Casanova M. New concepts for the treatment of pediatric nonrhabdomyosarcoma soft tissue sarcomas. Expert Rev Anticancer Ther 2005;5(2):307-18 